\title{
¡Rómpelo-tu-mismo! Historias del punk argentino y otras rebeldías porteñas
}


Daniel Flores es un experto en subculturas del rock. Hace años, el argentino, periodista de La Nación y músico, se dedica a reconstituir y registrar la história de las escenas rockeras a partir del final de la década de 70 en Argentina. Nacido en 1973, en los años 90 actuó como uno de los fundadores de las revistas de rock alternativas Esculpiendo Milagros y Revólver. En 2009, publicó La manera correcta de gritar, una historia del ska en Argentina, y Pintó el punk!, un librito para colorear las tapas de veinte discos de punk, incluyendo reseñas y comentarios sobre las bandas. Organizó y escribió, junto com otros autores, Gente que no: postpunks, darks y otros iconoclastas del under porteño en los 80 (2010) y Derrumbando la Casa Rosada: mitos y leyendas de los primeros punks en la Argentina. 1978-1988 (2011) - todos publicados por la editora Piloto de Tormenta'. En 2018, presentó su último libro, Remeras de rock, por la editora Tren en Movimiento ${ }^{2}$. Se trata de una colección ecléctica de crítica, ensayo, crónica de viaje y entrevista en torno al rock, las camisetas de rock y otros fetiches rockeros. Flores amablemente nos concedió la entrevista abajo, en la que hablamos del inicio del punk argentino, su relación con la moda, la construcción de su identidad visual y de su cultura material.

Además de la música, una de las cosas más impresionantes sobre el punk es el visual. Hoy, con la Internet y la rapidez de la información mediática, es difícil dimensionar el real impacto que las imágenes de las primeras bandas extranjeras, como el Sex Pistols y los Ramones, tuvieron en la juventud latinoamericana de finales de los años 1970 y principios de los 80. En el capítulo "Arde Belgrano", de Derrumbando la Casa Rosada, el autor Alfredo Sainz menciona el consenso entre los primeros punks porteños de que muchos se han convertido en fans de las bandas antes mismo de escuchar sus canciones, al ver sus fotos en las revistas de rock. Me gustaria comenzar nuestra conversación pidiéndole hablar un poco sobre ese inicio de una cultura punk en Argentina, de esa repercusión del visual inglés y norteamericano y de cómo fue emulado.

Los inicios de la escena punk o las escenas punks en Argentina se caracterizan, entre otras cosas, por la escasa información. Los jóvenes que adoptaron esta subcultura como propia, a su manera, lo hicieron a partir de pequeñas piezas de un rompecabezas, que finalmente completaban como podian, con sus propios aportes. Las fuentes podian ser breves artículos en revistas importadas o "grabaciones de grabaciones de grabaciones" de discos ingleses o norteamericanos, que llegaban a destino aún más distorsionados que los originales. Otro fenómeno interesante es que en Argentina tuvo una influencia determinante el punk "hecho" en España, particularmente en el País Vasco o Euskadi. Es decir que, a muchos chicos argentinos, el punk les llegaba en una versión ya "traducida", que a su vez ellos volvieron a interpretar desde su propia cultura. Luego, el punk "a la argentina" Ilegó así a otros países, como Uruguay y Bolivia y Perú, donde otros jóvenes volverían a reinterpretarlo todo. 
En la introducción del libro, usted comenta que las intencionalmente escandalosas esvásticas que los punks ingleses usaban quizá no serian tan mal vistas en Argentina, por el momento político en que se vivía. Es decir, a pesar de las similitudes entre el visual punk extranjero y el argentino, yo quería que usted contara un poco sobre las discrepancias. ¿Qué era particular a la escena porteña, cuáles eran los objetos, los símbolos, las frases de efecto, las consignas específicas del contexto argentino?

No son ideas "exclusivas", pero diría que el punk argentino, sobre todo el de los inicios del movimiento, tuvo una impronta particularmente politizada. Hay que recordar que el punk comenzó a tomar algún impulso aquí precisamente en el momento en que terminaba una dictadura militar y el país acababa de perder una guerra, por las islas Malvinas. También es interesante notar que el punk en Argentina (siempre concentrándonos en sus inicios, durante los años 80) fue profundamente antirreligioso, anticatólico y antipapal, algo no muy presente en Estados Unidos ni en Inglaterra, paises de por sí no tan religiosos, pero si muy visible en el punk español. En Argentina, la Iglesia católica es el establishment y fue un blanco predilecto de los punks. "Policia" fue otra palabra muy presente en aquellos inicios. La policía era precisamente uno de los mayores problemas de los jóvenes, quizás bastante más que hoy.

En cuanto a "objetos" algo interesante para remarcar es la "economía de recursos". Concretamente, el vestuario de aquellos primeros punks era una versión bastante más austera y extremadamente "hand made". No había en Buenos Aires ninguna tienda como la de Malcolm McLaren...

Usted también tiene un libro sobre el ska en Argentina, entonces voy a aprovechar para pedir ese análisis comparativo también en relación al ska. ¿Habia ese intercambio de referencias con las bandas de fuera? ¿El visual era el mismo o pasaba por adaptaciones?

El ska, por supuesto, llega un poco más tarde que el punk a la Argentina. Y de manera aún más limitada. En este caso, se podrian repetir muchos de los términos ya comentados sobre el punk: poca información, discos re-grabados hasta el infinito y muchos "vacíos" Ilenados con lo que se podía, lo que estaba a mano. Claro que, si el punk fue una escena marginal, el ska fue entonces aún más restringido, un gueto muy pequeño, casi familiar.

En el transcurso de los capítulos de Derrumbando la Casa Rosada, es notable la presencia femenina en el punk argentino. Uno de ellos, "La bataIla del Riachuelo", fue escrito por Patricia Pietrafesa, figura bastante activa del movimiento y miembro de diversas bandas punk. ¿Podrías hablar un poco sobre lo que era ser chica en el origen de la escena?

Es curioso. Pensar en el lugar de la mujer, incluso en una escena como el punk, hoy es irrisorio. Las mujeres tuvieron una participación muy limitada en esos años, más allá del rol destacado, como bien mencionas, de alguien como Patricia Pietrafesa, música, editora de fanzine, organizadora de 
festivales y gran agitadora, que siempre intentó "llenar" aquellos vacíos de información que mencionaba, con contenido relevante. Hubo otras mujeres, claro, como la banda femenina Exeroica o algunas otras integrantes de grupos. Los testimonios siempre coinciden en recordar el ambiente como muy machista y difícil para las chicas. La sociedad, en ese sentido, tenía mucho por avanzar y el punk, aunque detestara reconocerlo, no escapaba a esa problemática.

En el punk inglés, en relación a la moda, se destacó la actuación de Vivienne Westwood, en la época esposa de Malcolm McLaren y, se dice, responsable de vestir y producir la imagen de varias bandas (incluso de los Sex Pistols). ¿Hay algún personaje análogo en el punk argentino, algún nombre que haya actuado junto a las bandas o que sea referencia de ese estilo?

Realmente no puedo pensar en ningún personaje análogo a Vivienne Westwood en Argentina. Creo recordar que existió una tienda de estilo entre "gótico" o "new romantic" Ilamada Kamasutra, por ejemplo, pero definitivamente los punks de entonces no aprobaban ese tipo de consumos... En el vestuario, el "hazlo-tu-mismo" era la norma. incluso se podría hablar acá, más bien, del "rómpelo-tu-mismo"! Lo pantalones y las camisetas con agujeros y desteñidos eran furor.

En 2013, el Costume Institute, del Metropolitan Museum de Nueva York, organizó la exposición PUNK: Chaos to Couture, sobre la historia y la influencia del punk en la moda y la cultura en general. En el montaje, una sección entera estaba dedicada a las camisetas mal hechas y estampadas artesanalmente, ejemplificando el DIY practicado por aquellos jóvenes. Se sabe, sin embargo, y eso queda claro en Derrumbando la casa rosada, que el punk valoraba lo desechable, lo deshecho, lo efímero. ¿Parece, para ti, una paradoja que los artículos del punk se hayan convertido en objetos de exposición en un Museo? ¿Ya hubo alguna iniciativa así en relación al punk argentino?

Es una paradoja, si. Pero una paradoja esperable de este mundo en el que todo parece tener destino de "producto" o de pieza de museo. Sin embargo, me parece importante destacar en este punto que no todo el punk, ni en la música ni en la estética, ha sido apropiado por "el sistema". Más allá de muestras como esa, hay mucha música (la mayor parte, por cierto) que sigue representando un desafio al mainstream.

Respecto a si hubo ya una muestra así en Argentina, no, no la hubo. Sí puedo comentarte que nuestro libro, Derrumbando la Casa Rosada, se presentó oficialmente en el Museo del Libro y de la Lengua, parte de la Biblioteca Nacional Argentina. Quizás ese sea un ejemplo local del punk irrumpiendo en una institución cultural "oficial". 
Usted ha lanzado recientemente un nuevo libro, llamado Remeras de rock. La camiseta de banda tal vez sea una de las pocas unanimidades entre los fans de rock, independiente de la vertiente, pues ella es un "poderoso artefacto comunicacional", como usted define en el libro, expresando la individualidad y también la pertenencia a un grupo. Pero esas motivaciones contrastan con el fenómeno mercadológico de las camisetas de banda, que usted también destaca en el libro. La camiseta de banda - de cualquier banda - puede convertirse en mero producto, consumido por quien ni la conoce y nunca oyó sus canciones. Yo quería que usted hablara un poco sobre eso, sobre esa prenda al mismo tiempo tan simple y tan cargada de significados y de su banalización por el consumo de masas.

Es un tema amplio y, como bien lo decís, lo desarrollo en el libro. Algo que podría agregar acá es una particularidad de los comienzos del punk en Argentina (y aclaremos que cuando hablo de Argentina hablo en verdad de Buenos Aires, mayormente). Los punks de los 80 pintaban sus propias camisetas. Lo hacian ellos mismos, se lo pedian a un amigo con habilidades plásticas o incluso se lo podian encargar a una tienda especializada en "copiar" a mano, sobre tela, fotos o tapas de discos, lo que el cliente quisiera. Debido a la falta de recursos, el "hazlo-tu-mismo" era realmente total. No era solo una elección: no quedaba alternativa.

257 ] $\quad Y$ es cierto que en esa escena podía ocurrir lo que hoy sucede, por ejemplo, con los Ramones a nivel masivo: algunos chicos se "plegaban" al culto a determinadas bandas sin haberlas escuchado. Un caso paradigmático es el de los Dead Kennedys, cuyo logotipo con la D y la K era mucho más reproducido que su música en Buenos Aires. Era un logo especialmente poderoso y fácil de copiar, y eso provocó que su nombre circulara muy fuertemente, mucho más que otros grupos.

Para terminar: en Remeras de rock, usted menciona el caso de la clásica camiseta de los Ramones, con el logo del águila y los nombres de los integrantes alrededor, cuyo recorrido va del antiestablishment en su surgimiento, pasando al stylist de las celebridades y llegando a las grandes tiendas minoristas de ropa. Tal vez un nuevo capítulo de esa trayectoria surgió aquí en Brasil, en las últimas elecciones presidenciales, en noviembre, cuando los votantes del candidato de extrema derecha y admirador confesado de Donald Trump, Jair Bolsonaro, crearon versiones de la camiseta de los Ramones, por ejemplo, con el escudo nacional y los nombres de los hijos del político. ¿Cómo ves ese tipo de resignificación de uno de los símbolos del punk, que él podría indicar sobre nuestra relación con el punk en la contemporaneidad? ¿El punk todavía existe?

¡Increíble lo de Bolsonaro-Ramones! No conocía el fenómeno. En Argentina, Máximo Kirchner, hijo de la ex presidenta Cristina Kirchner, está siendo investigado en distintas causas por supuesta corrupción. Él y su familia. Recientemente, Máximo apareció en público con una camiseta 
del disco de Metallica And Justice For All, apropiándose del "mensaje" y del clásico disco de la banda, para su propia causa.

Más allá de Bolsonaro, desde ya que considero que el punk existe. Los Ramones son una banda genial, que me gusta mucho, pero lo cierto es que fueron de algún modo una escena en sí mismos. Me cuesta un poco verlos como "representantes" de algo más amplio que ellos mismos $y_{1}$ en todo caso, las legiones de sus imitadores. Cuando pienso en punk pienso más bien en música "menos amable", por un lado, y también pienso en una operación independiente, marginal, autogestionada. La verdad, me cuesta pensar en los Ramones como ejemplo de eso. Bolsonaro o sus seguidores tomaron el logo de los Ramones, pero no los imagino adaptando los logos de Doom o utilizando para su campaña una canción de Poison Idea... El punk existe y es ese lugar que los Bolsonaro de este mundo ni siquiera saben dónde queda. 